\title{
Eski Eserlerdeki Yapısal Tahribatların Termal Görüntüleme ve Mikrodalga Nem Ölçümleri ile Belirlenmesi: Ayasofya Müzesi Örnek Çalışması
}

\author{
Cahit Çağlar Yalçıner ${ }^{*}$, Erdem Gündoğdu², Yunus Can Kurban ${ }^{3}$, Erhan Altunel ${ }^{4}$ \\ ${ }^{1,2}$ Çanakkale Onsekiz Mart Üniversitesi, Çan Meslek Yüksekokulu, Madencilik ve Maden Çıkarma Bölümü \\ ${ }^{3}$ Eskişehir Osmangazi Üniversitesi, Fen Bilimleri Enstitüsü, Jeoloji Mühendisliği ABD \\ ${ }^{4}$ Çanakkale Onsekiz Mart Üniversitesi, Mühendislik Fakültesi, Jeoloji Mühendisliği Bölümü
}

24.10.2017 Geliş/Received, 06.12.2017 Kabul/Accepted

\section{Özet}

Ülkemizde güncel olarak tarihi önem taşıyan binaların restorasyonuna büyük önem verilmektedir. $\mathrm{Bu}$ tarz önemli tarihsel geçmişe sahip binalarda restorasyon çalışması yapılmadan önce deformasyonların ve bozulmaların nedenini araştırmak da çok büyük önem taşımaktadır. Gelişen teknolojik aletler sayesinde restorasyon çalışmaları öncesinde deformasyon ve nedenlerini tahribatsız yöntemler ile belirlemekte mümkün olmaktadır.

Yapımı M.S. 537 yılında tamamlanan ve İstanbul'un fethi sonrasında cami olarak kullanılmaya başlanan Ayasofya Müzesi'nin (Hagia Sophia) ana kubbesi, birçok kez çökerek hasara uğramış; 16. yy da ise Mimar Sinan tarafından yapılan istinat duvarı ve payandalar ile bu hasarlar önlenmeye çalışılmıştır. Ana kubbedeki bu hasarların yanı sıra, bina içerisinde de meydana gelen yapısal hasarlar mevcuttur. Bu hasarların önlenmesi amacıyla da, başta galeri katı olmak üzere binada bulunan taşıyıcı elemanlar, metal ve ahşap hatıllar ile desteklemiştir. $\mathrm{Bu}$ güçlendirmelerden sonra, bölgede birçok deprem meydana gelmesine rağmen, Ayasofya'da yıkıma yol açan bir deprem olduğuna dair herhangi bir kayıt bulunmamaktadır. Tüm bu güçlendirme çalışmalarının yanı sıra, 1930'lu yıllarda Mimar Fossatti kardeşler tarafından ana kubbeye tadilat ve güçlendirme çalışmaları da yapılmıştır. Günümüzde birçok ziyaretçi tarafından yoğun olarak ilgi gören Ayasofya'da, özellikle galeri katında zeminde ve duvarlarında yer alan bu deformasyonların varlığı dikkat çekmektedir.

Yap1 radarı sonuçlarında tespit edilen duvarlardaki bozulma ve deformasyonların nedeninin araştırılması amacı ile termal görüntüleme ve mikrodalga nem ölçümleri gerçekleştirilmiştir. Elde edilen sonuçların verdiği görüntü yapı radarının tespitlerine 1 şık tutacak şekilde olmuştur.

Ayasofya Müzesi Galeri Katında yapılmış olan termal görüntüleme işlemi ve noktasal mikrodalga nem ölçümleri yapının maruz kaldığı ve kalacağı sorunları göstererek tahribatsız muayene işlemlerinde başarılı olarak kullanılabileceğini ortaya koymuştur. Bu tarz çalışmalar gerek tarihsel önemi gerekse günümüz ziyaretleri ile ekonomik önemi bulunan yapının korunmasında büyük önem taşımaktadır.

Anahtar Kelimeler: termal görüntüleme, mikrodalga nem ölçümü, Ayasofya.

\footnotetext{
*Sorumlu Yazar (Corresponding Author): Cahit Çağlar Yalçıner (e-posta: yalciner@comu.edu.tr)

Bu makale; Çanakkale Onsekiz Mart Üniversitesi Bilimsel Araştırma Projeleri Koordinasyon Birimince desteklenmiştir. Proje numarası: FBA-2016-803
} 


\title{
Determination of Structural Destruction of Ancient Monuments with Thermal Imaging and Microwave Humidity Measurements: Sample Study of Hagia Sophia Museum
}

\begin{abstract}
In Turkey currently the restoration of buildings with historical significance is given great importance. Before restoration work on these types of buildings with historical significance, it is very important to research the causes of deformation and disruption. Due to developed technological tools, it is possible to determine deformation and causes with non-destructive methods before restoration work.
\end{abstract}

The main dome of Hagia Sophia Museum, with construction completed in 537 AD and used as a mosque after the conquest of Istanbul, has collapsed and been damaged several times. In the 16th century Mimar (architect) Sinan attempted to prevent this damage by constructing retaining walls and buttresses. In addition to this damage to the main dome, there is structural damage that has occurred within the building. With the aim of preventing this damage, all supporting elements within the building, led by the gallery floor, were supported with metal and wooden beams. After this reinforcement, there is no evidence of any earthquake causing destruction to Hagia Sophia in spite of many earthquakes occurred in the region. In addition to all these reinforcement works, in 1930 the architect Fossatti brothers performed repair and reinforcement work to the main dome. A focus of intense interest currently with many visitors, there is noteworthy deformation in Hagia Sophia, especially on the floor of the gallery and in the walls.

With the aim of researching the causes of disruption and deformation identified in the walls with structural radar studies, thermal imaging and microwave humidity measurements were completed. The images obtained as a result shed light on the findings of the structural radar study.

Thermal imaging processes and point microwave humidity measurements performed on the gallery floor of Hagia Sophia Museum show the problems the structure has been and will be exposed to and reveal that non-destructive examination processes may be successfully used.

These types of studies carry great importance in preserving structures with both historical importance and economic importance due to current visitor numbers.

Keywords: thermal imaging, microwave humidity measurements, Hagia Sophia

\section{Giriş}

İnsanlık tarihinin gerek dinler gerekse medeniyetler açısından en önemli eserlerinden olan Ayasofya Müzesi, geçmişte yaşadığı çeşitli doğal afetler (deprem gibi) ve insan eliyle oluşan yangın gibi etkili afetler sonucunda birçok kez yeniden inşaata kadar giden yenilemeler geçirmiştir. Ancak günümüzdeki durum zamana karşı oluşan bozulmalar sonucunda binanın yıpranması ile yakından ilişkilidir. En büyük yenileme çalışmalarından birini yapan Mimar Sinan, yapının tüm taşıyıcı sistemini etkileyecek şekilde yaptığı düzenlemelerle binanın bugünlere gelmesini sağlamıştır. 
Çalışmanın esasını oluşturan tarihi yapıların mevcut hasar durumlarının nedenlerinin ve gelecekte olabilecek hasarların önlenmesi, ülkemizde yürütülen birçok restorasyon projesi için hayati önem taşımaktadır. Bir çok bilim dalının ortak çalışmalar gerçekleştirdiği bu tarz restorasyon çalışmalarında tahribatsız araştırma yöntemleri ile yapılan hasar tespit ve 3 boyutlu görüntüleme çalışmaları önemli bir yer tutmaktadır.

Ülkemizde de yüksek teknolojik cihazlar ile gerçekleştirilen bu tarz çalışmalara yeni bir boyut kazandırmak amacı ile termal görüntüleme ve mikrodalga nem ölçümlerinin aynı anda kullanılması amaçlanmaktadır. Bu çalışma aynı zamanda bir araştırma projesi kapsamında da (Yalçıner ve Gündoğdu., 2017) gerçekleştirilmiş olup; bu çalışmayı gerçekleştiren proje ekibi uzun süredir tarihi yapıların tahribatsız araştırmalarında çalışmalar gerçekleştirerek, bu tarz uygulamaların yaygınlaştırılmasına katkı sağlamaktadır.

Yapı Radarı yardımı ile 3 boyutlu görüntülenmesi tamamlanmış olan Ayasofya Müzesi (Şekil 1.1) galeri katında bulunan bozulmaların duvar içerisindeki büyük kısmının 1slaklık ve nem nedeni ile oluştuğu düşünülmektedir. Yapılacak termal görüntüleme ve mikrodalga nem ölçümleri ile tespit edilecek bozukluklar ve nedenleri ortaya konarak, hem çok büyük öneme sahip bu yapının restorasyonuna katkı sağlanacak hem de bundan sonra yapılacak çalışmalara önderlik edecek sonuçlara ulaşılacaktır.

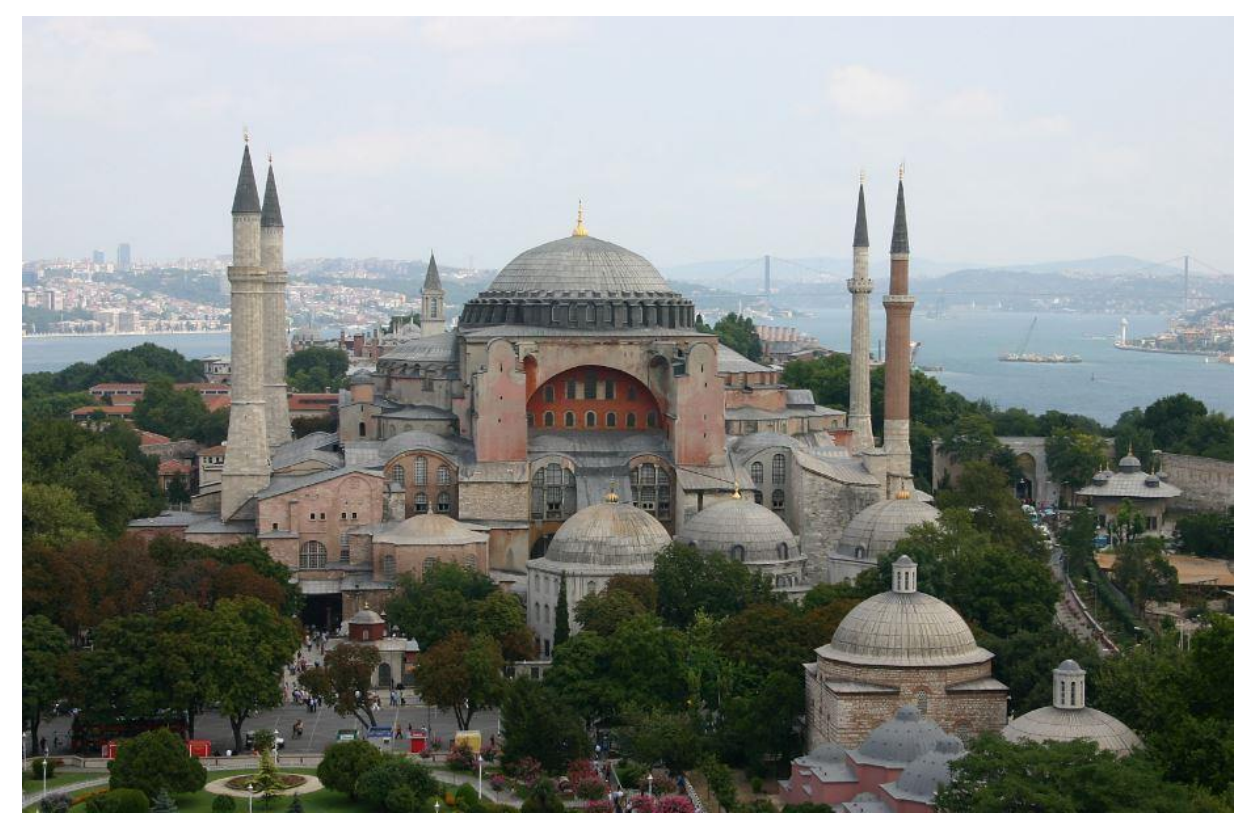

Şekil 1.1. Ayasofya’dan bir görünüm (http://ayasofyamuzesi.gov.tr/tr/foto-galeri)

Ayasofya Müzesi Galeri Katı duvarlarında 1slaklık ve neme bağlı deformasyonların yerlerinin ve nedenlerinin tespiti bu çalışmanın konusunu oluşturmaktadır. Çalışma kapsamında galeri katı duvarlarında belirlenen bölgenin termal görüntüleme ve mikrodalga nem ölçümleri ile taraması yapılacaktır. Çalışmanın amacına uygun ölçümlerin toplanması ile elde edilecek sonuçlar restorasyona bilgi teşkil ederken ileride yapılacak bu tarz çalışmalara da 1 şık tutacaktır.

\section{Yöntem}

Termal görüntüleme ve mikrodalga nem ölçümleri, yıllardır inşaat sektöründe kullanılan modern ekipmanlardandır. Bu çalışma kapsamında kullanılan cihazlar, tarihi yapılarda kullanılmaya uygun ve yüksek hassasiyetli olmalıdır. Bu doğrultuda, termal görüntüleme 
sağlayacak kamera sisteminin hassasiyeti en az $\pm 2 \mathrm{C}^{0}$, görüntü yakalama sıklığ $9 \mathrm{~Hz}-60 \mathrm{~Hz}$ ve kızıl ötesi spektral bandı $7.5 \mu \mathrm{m}-14 \mu \mathrm{m}$ arasında olmalıdır. Nem ölçümlerinin yapılacağı Mikrodalga nem ölçerde ise, hassasiyet 0.1 basamak ve etki derinliği $30 \mathrm{~cm}$ olmalıdır.

\subsection{Termal Kamera}

Termal kamera, genel olarak alanların ve parçaların normal değerinden farklı 1sı değerlerini ölçen bir cihaz olup, lens ve algılayıcılardan oluşur. Termal kameralar, ölçümü yapılacak nesneler ile doğrudan teması olmadan sıcaklık modellerini algılama özelliğine sahiptir. İnsanlar tarafından hissedilemeyen 1sı değerlerini (IR enerji), bu enerjiye göre meydana gelen renk ve şekiller yardımıyla belirlemeye çalışan bir cihazdır (Evangelisti, 2015). Bu sayede, büyük problemlere neden olabilecek ancak dişarıdan hissedilmeyen unsurların belirlenmesi sağlanır (Değirmenci, 2010; Berkmen, 2001: Young, 2014; Nikzad ve ark., 2011; Kosikowski ve Suszynski, 2011; Faundez ve Mekyska, 2011; Cox-Smith, 2010; Bianchi ve ark., 2014; Pleşu ve ark., 2012)) (Şekil 2.1). Termal kamera ölçümlerinin doğruluğunu teyit amacı ile ölçümler farklı günlerde ve farklı saatlerde yapılarak çevresel ortamlardan oluşabilecek etki faktörleri araştırılmıştır. Bu etkilerin giderilmesi ile cihazın olası sapma değerleri ortadan kaldırılmıştır. Bu sayede cihazın kalibrasyon ihtiyacı da "self-calibration" (kendi içerisinde kalibre) olarak giderilmiştir.

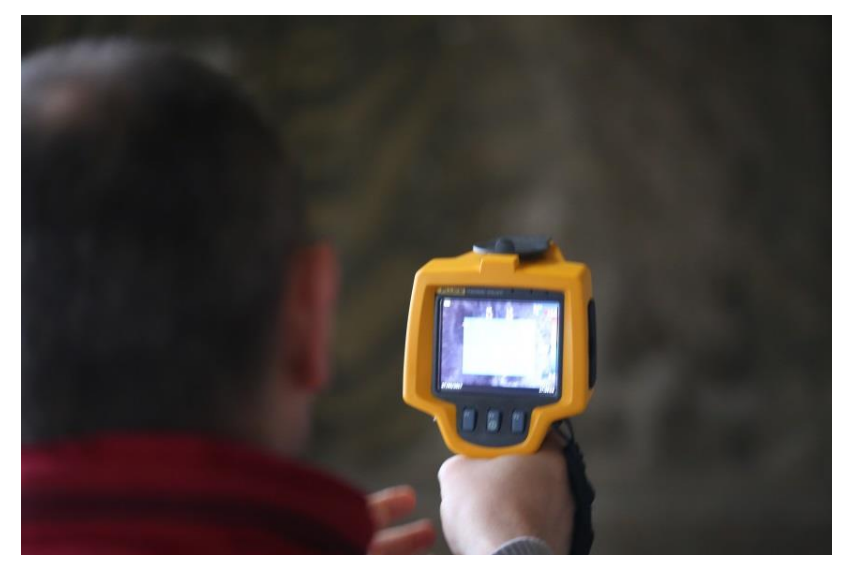

Şekil 2.1. Ayasofya'da kullanılan termal görüntüleme cihazı (Ti110 9Hz/NFC Fluke Thermal Imager, 9Hz).

Termal kamera ile ortaya konulan 1sı haritalarında (1s1 fotoğrafları), nispeten sıcak bölgeler açık renkle, soğuk bölgeler ise koyu renkle anomali vererek 1slaklık teşkil eden bölgelerin belirlenmesi sağlanır. Termal kameralar renkli veya siyah-beyaz olacak şekilde ortamın is1 durumunu yansıtır. Renkli termal kameralarda, 1sı skalası maviden sarıya doğru kırmızı rengi kullanarak geçiş sağlar. Bu 1sı skalasında mavi renk en soğuk bölgeyi, sarı renk ise en sıcak bölgeyi temsil eder (Berkmen, 2001) (Şekil 2.2). 

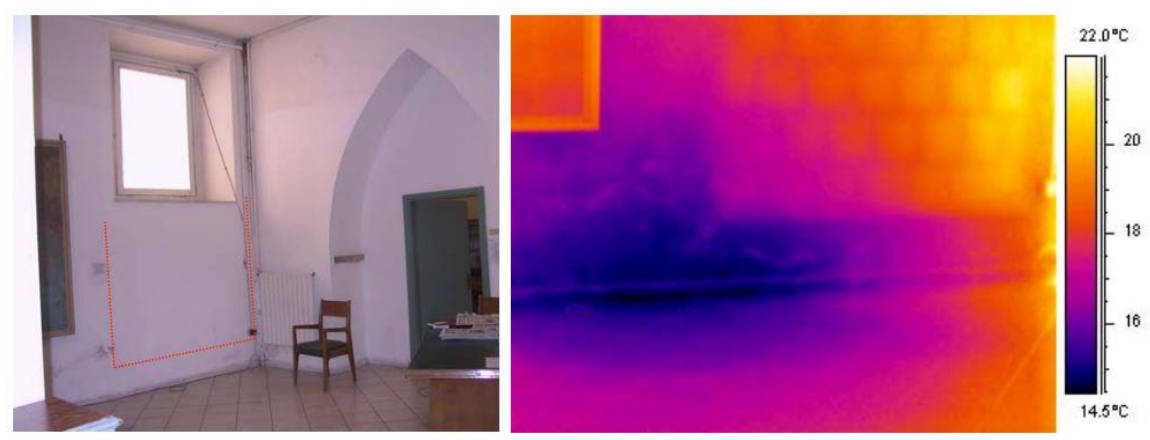

Şekil 2.2. Nemliliği bilinen bir alanda yapılan termal görüntüleme sonucu yapıya ait değerlerin belirlenmesi (Grinzato, 2012).

Termografi (termal video / termal görüntüleme) bir kızılötesi görüntüleme çeşidi olup, elektromanyetik spektrumun kızılötesi alanındaki $(0.9-14 \mu \mathrm{m})$ elektromanyetik 1şınımın belirlenmesini sağlar. Termografi; itfaiyecilik, güç hatlarındaki aşırı 1sınma alanlarının tespiti ve onarımı, izolasyonda sorunlarının tespiti gibi birçok alanlarda çeşitli kullanım alanlarına sahiptir (Anonim, 2017)

\subsection{Mikrodalga Nem Ölçer}

Bir malzemenin nem oranı, o malzeme üzerinden geçen mikrodalga gücündeki zayıflama ile, nem oranı arasındaki ilişkinin belirlenmesi ilkesine dayanır. İçeriğinde nem barındıran bir malzemenin mikrodalga gücündeki zayıflık miktarı, o malzemenin içeriğindeki yalıtkanlık kayıp faktörü ile ilişkilidir. Bilindiği gibi malzemelerin yalıtkanlık özellikleri frekansa bağlı olarak değişim göstermektedir. Bu sebepten dolayı, sistemin çalışma frekansının seçimi büyük önem taşımaktadır. Örneğin suyun, yalıtkanlık kayıp faktörü ile, malzeme içindeki suyun yalıtkanlık kayıp faktörü farklı değerlere sahip olup, bu çalışmada çalışma frekansı $2.45 \mathrm{GHz}$ seçilmiştir (Brodwin ve Benway, 1980; Chaloupka ve ark., 1980; Kraszewski ve ark., 1996; Kraszewski, 1980; Nelson ve ark., 1992). Nem ölçümlerinde kullanılan cihazın özelliği açısından bağıl nem ölçümü gerçekleşmektedir. Bu nedenle cihazın ölçüm esnasında kalibrasyon işlemi için ortamda cihazın havaya tutularak sıfırlaması yapılmaktadır. Sonrasında ise en az " 0 ” en çok “200” birim olacak şekilde bağıl nem ölçülmektedir.

Bir mikrodalga uygulayıcısı içine yerleştirilen malzemenin mikrodalga gücündeki zayıflığın belirlenebilmesi için, uygulayıcının giriş ve çıkış uçlarındaki mikrodalga gücünün ölçülmesi gerekir. Yeni geliştirilen sistemler ile ölçümler daha hızlı ve tek bir kullanıcı ile yapılabilmektedir (Şekil 2.3).

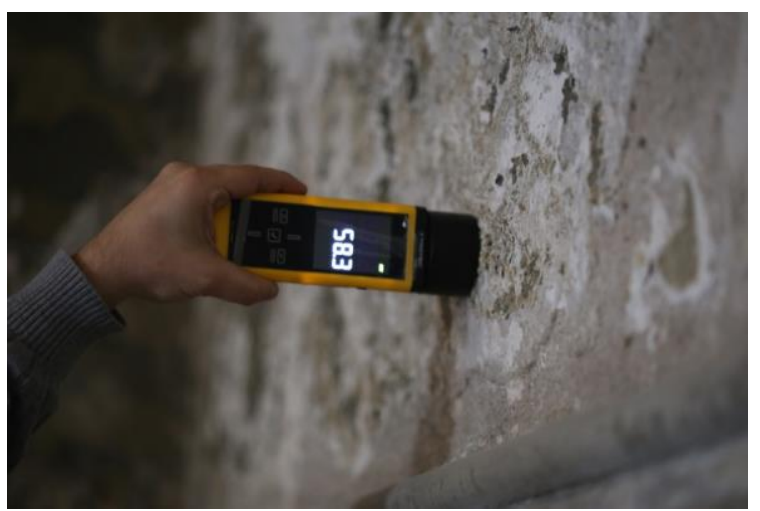

Şekil 2.3. Ayasofya Müzesi çalışmalarında kullanılan mikrodalga nem ölçer (Trotec T 610, Almanya). 


\section{Saha Çalışmaları ve Bulgular}

Çalışmanın oluşum sebebi olan ekip tarafından daha önce gerçekleştirilmiş olan Ayasofya Müzesi Galeri katının duvarlarındaki Yapı Radarı (GPR-CX) çalışmaları (Şekil 3.1) 1şığında termal görüntüleme ve mikrodalga nem ölçümleri gerçekleştirilmiştir. Bu bağlamda GPR-CX ölçümlerinde en sorunlu görülen bölgede yoğunlaşarak hem termal görüntüleme hem de nem ölçümleri yapılmıştır (Şekil 3.2).

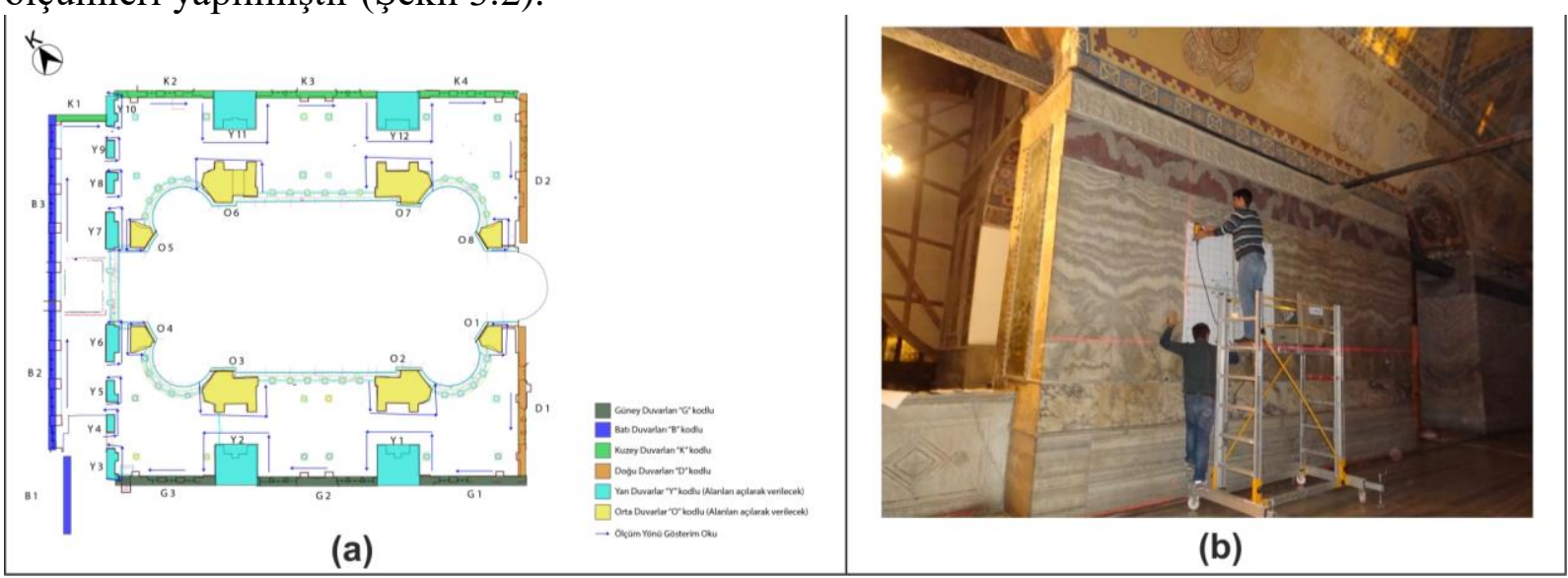

Şekil 3.1. (a) Daha önce gerçekleştirilmiş olan Ayasofya Müzesi çalışmalarında GPR-CX ölçüm yerlerinin gösterimi. (b) $2.3 \mathrm{GHz}$ frekanslı antenli MALA CX Monitorlü GPR-CX ölçümleri. 


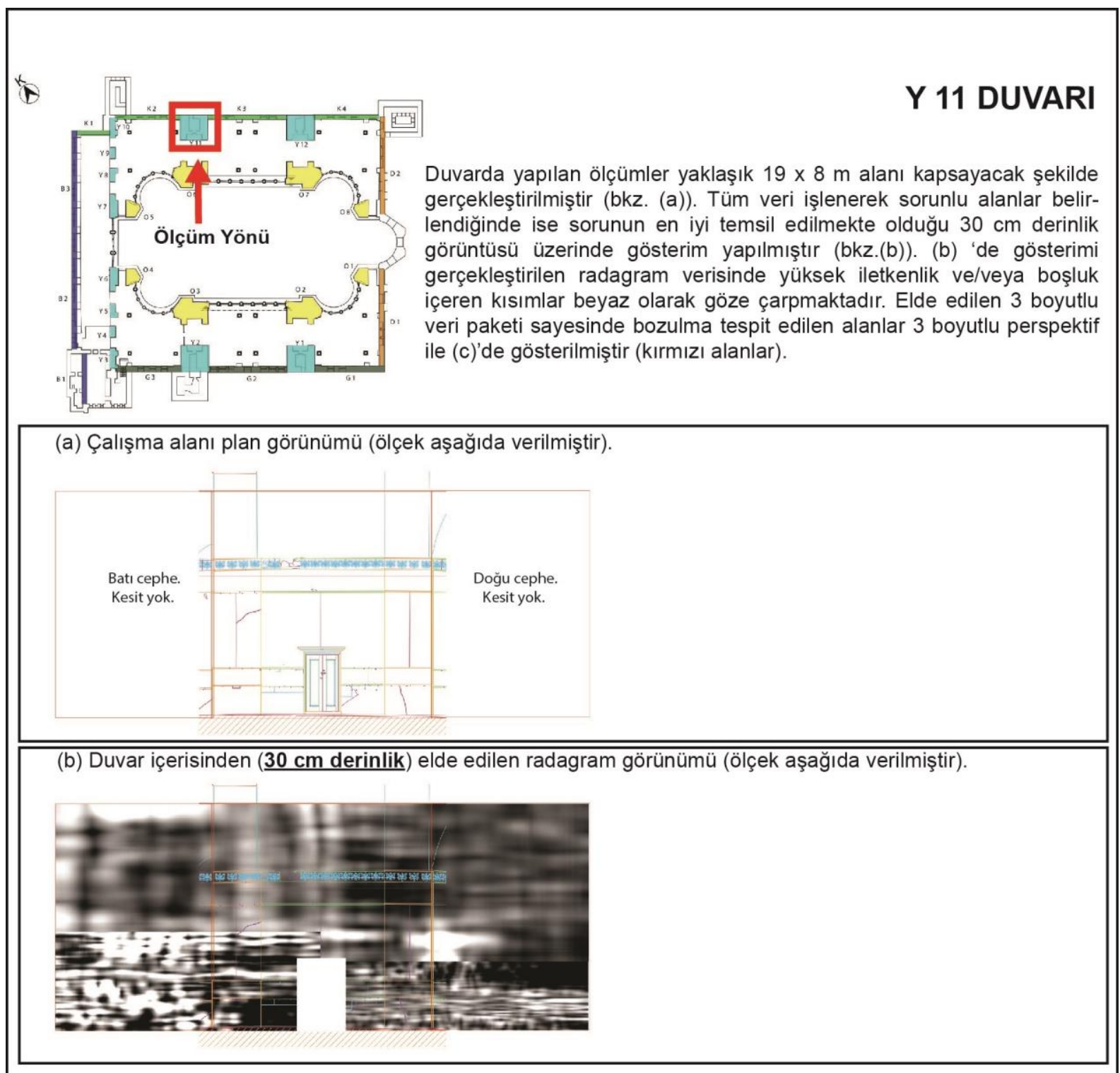

(c) Bozunmaların (ıslaklık ve/veya boşluk) yapılarının duvar içindeki konumlarını gösterir 3 boyutlu perspektif gösterim (bakış yönü ölçüm yönüdür).
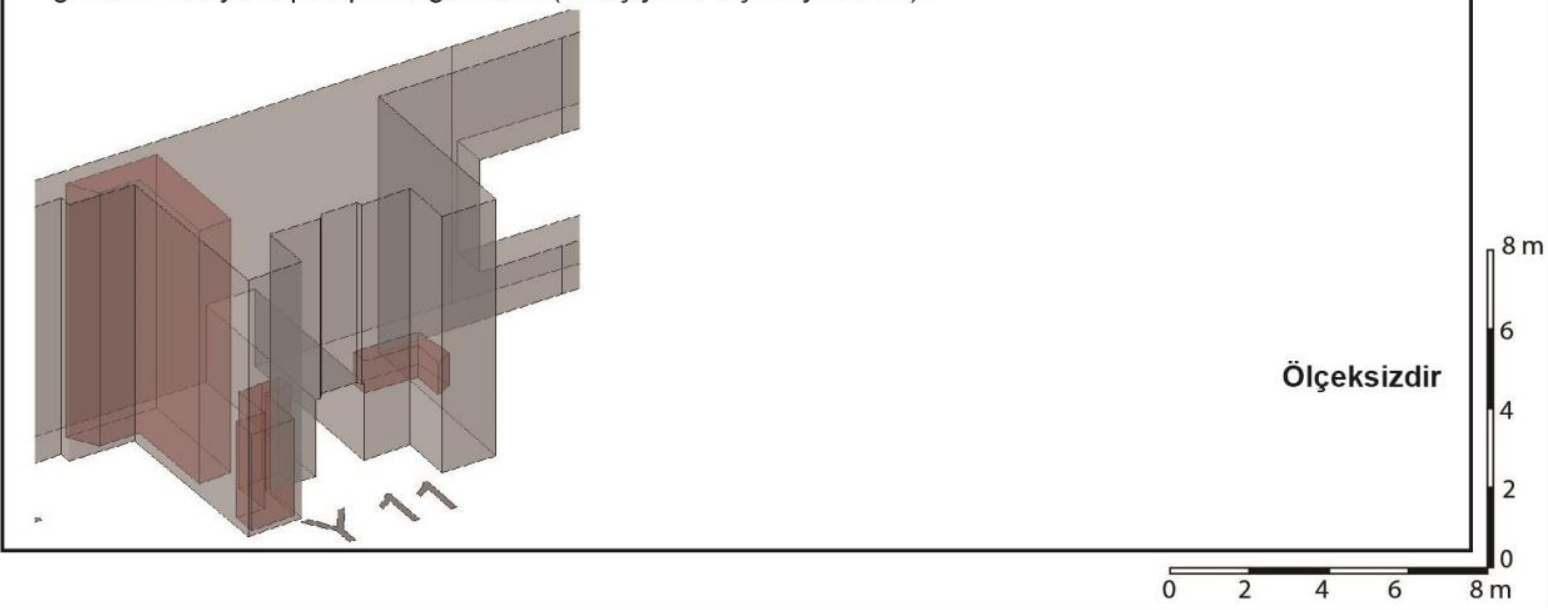

Şekil 3.2. GPR-CX ölçümlerinde en yoğun sorun tespit edilen (Y11 duvarı) bölgeye ait plan ve GPR-CX verilerinin gösterimi.

Çalışmada belirlenen bölgeler lazer işaretleyiciler ile işaretlenerek her iki ölçümünde birbirleri ile karşılaştırılması sağlanmıştır (Şekil 3.3). 


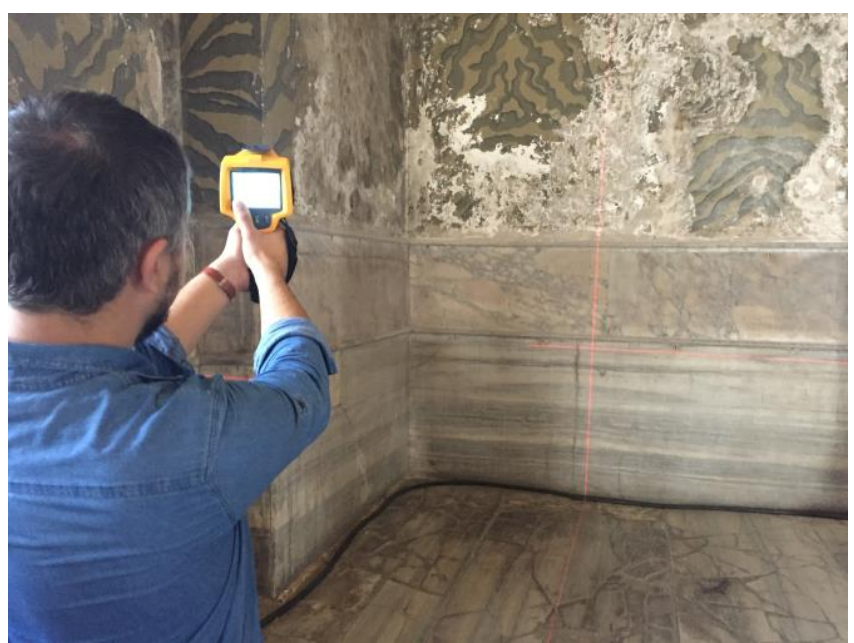

Şekil 3.3. Duvar ölçümlerinde kullanılan hizalama lazerinin ve termal görüntüleme ölçümünün gösterimi.

\subsection{Termal Kamera Ölçümleri}

Termal kamera ölçümleri genel anlamda geniş açıdan yapıldığında büyük alanları ölçen ancak yeterli çözünürlüğe ulaşamayan çalışmalardır. Bu nedenle çalışmada ölçüm için seçilen duvarın hem genel görünüşünün termal görüntüsü (tek termal görüntü ile elde edilen görüntü) (Şekil 3.4) hem de önceden yapılmış olan yapı radarı çalışmalarında sorunlu olduğu bilinen kısımlarının detaylı görüntüsü (bölgenin daha küçük alanlar ile ölçülüp birleştirilen termal görüntüsü) (Şekil 3.5) alınarak değerlendirilmiştir. Ölçüm gerçekleştirilen bölgede elde edilen görüntüler cihazın kendi çözünürlüğüne bağlı olarak optik açıdan iyileştirme amacı ile sayısal yakınlaştırma yerine fiziksel yakınlaştırma kullanılarak yapılmıştır. Termal kameradan elde edilen veriler sayısal olarak Surfer (Golden Software, ABD) programında gridlenerek (Kriging metodu kullanılarak) termal görüntü oluşturulmuştur. Oluşturulan grid için genel görüntüde tek bir verinin sayısallaştırılması kullanılırken (71 noktasal ölçüm), detay görüntüde ise 4 verinin sayısallaştırılması (284 noktasal ölçüm) kullanılmıştır.

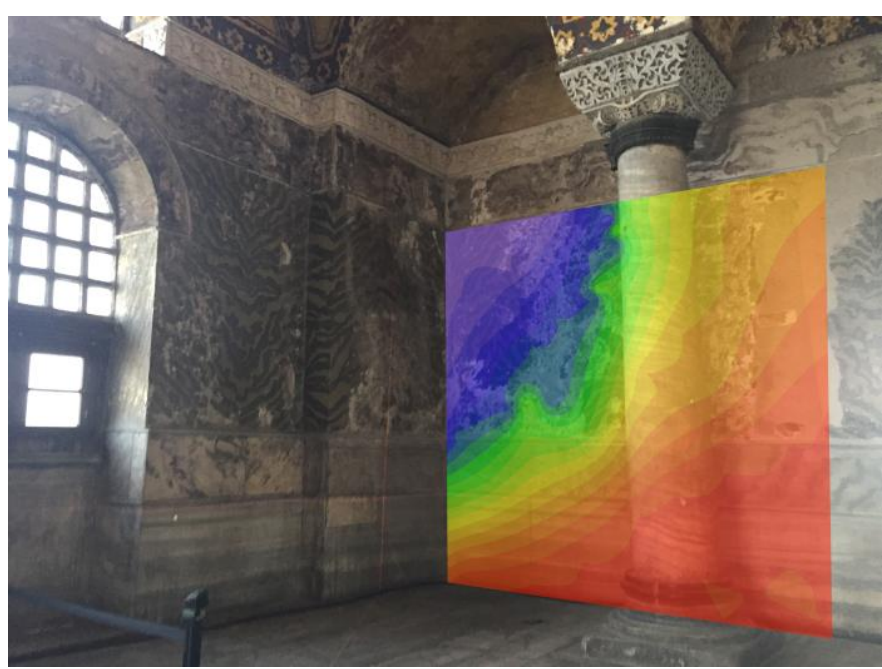

Şekil 3.4. Ölçüm için seçilen duvarın genel termal görüntüsü. 


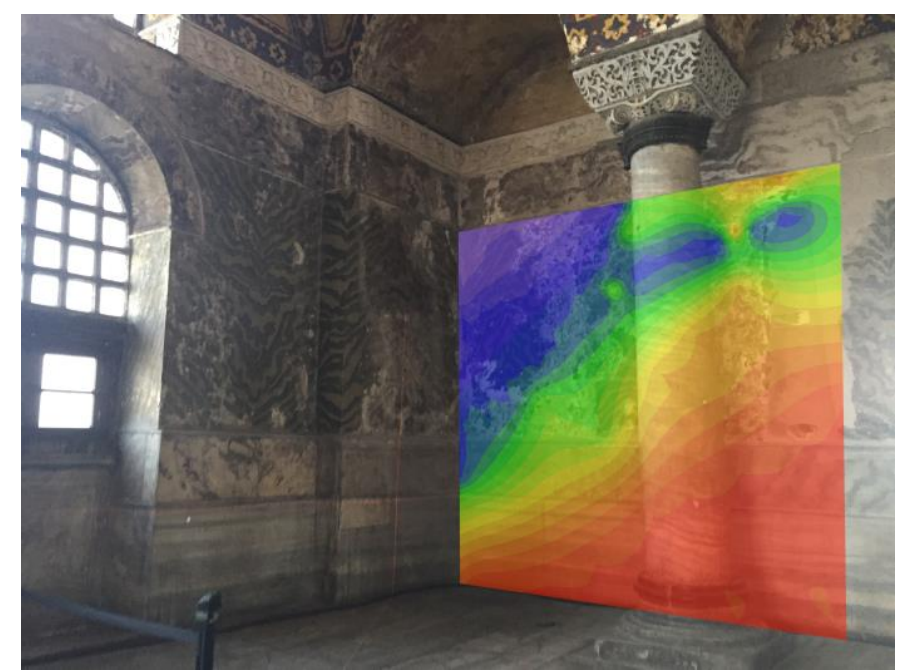

Şekil 3.5. Şekil 3.4'de gösterilen duvarın örnek detay görüntüsü.

Elde edilen detay görüntüler ise birbirlerine birleştirilerek, duvarın tamamına ait termal görüntü oluşturulmuştur (Şekil 3.6-a). Veri olarak 4 kat fazla noktasal ölçüm kullanılan detay görüntülemede çözünürlükte aynı oranda artmaktadır (Şekil 3.6-b).

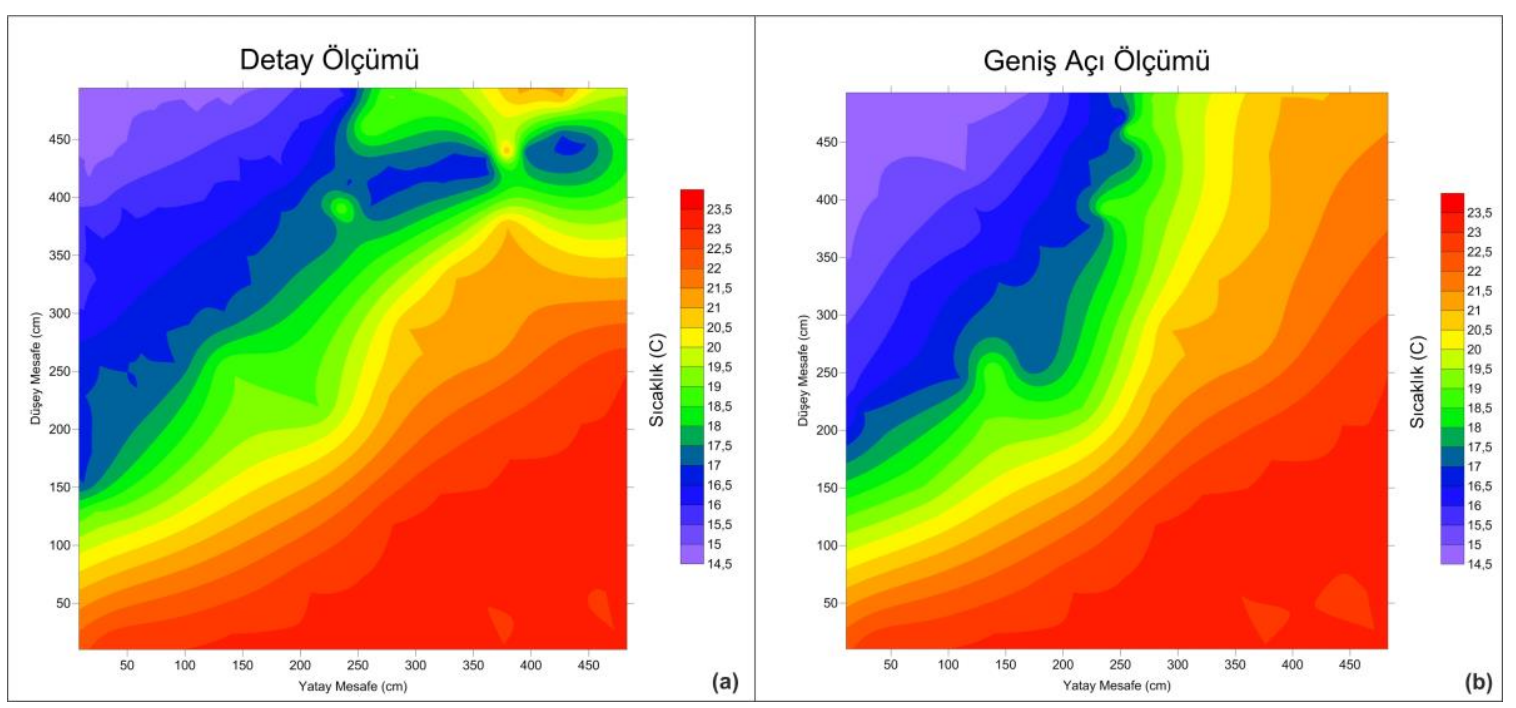

Şekil 3.6. (a) Detay görüntülerden oluşturulmuş termal harita. (b) Geniş açıda oluşturulmuş termal harita (Mavi soğuk bölgeleri ifade etmektedir).

Gerek genel haritada gerekse detay termal haritasında "mavi” ile gösterilen soğuk bölgeler nem oranın yüksek olduğu yerleri işaret etmektedir. Mavi rengin dolayısıyla soğuk bölgelerin yoğun olduğu yerlerde de nem oranın yüksek olduğu düşünülmektedir (günün farklı saatleri içinde yapılan ölçümlerde 1şık farklılığı elimine edilmiştir).

\subsection{Mikrodalga Nem Ölçümleri}

Kullanılan mikrodalga nem ölçer bağıl olarak sıfırlanma değerini esas alıp daha sonraki ölçüm noktalarının değerlerini bu sıfır üzerinden vermektedir. Bu nedenle mikrodalga nem ölçümleri yere paralel hatlar ile yapılarak grafiklenmiş (Şekiller 3.7 ve 3.8) ve bu grafikler Golden Software Surfer programında gridlenerek (Kriging metodu kullanılarak) 3 boyutlu görüntü oluşturulmuştur (Şekil 3.9). Kullanılan Surfer programındaki gridleme aşamasında 
herhangi bir ön filtreleme aşaması yapılmamıştır. Herhangi bir dış etken olmaması için kendi içerisinde kalibre edilen veriler ham hallerinde gridlenmiştir.
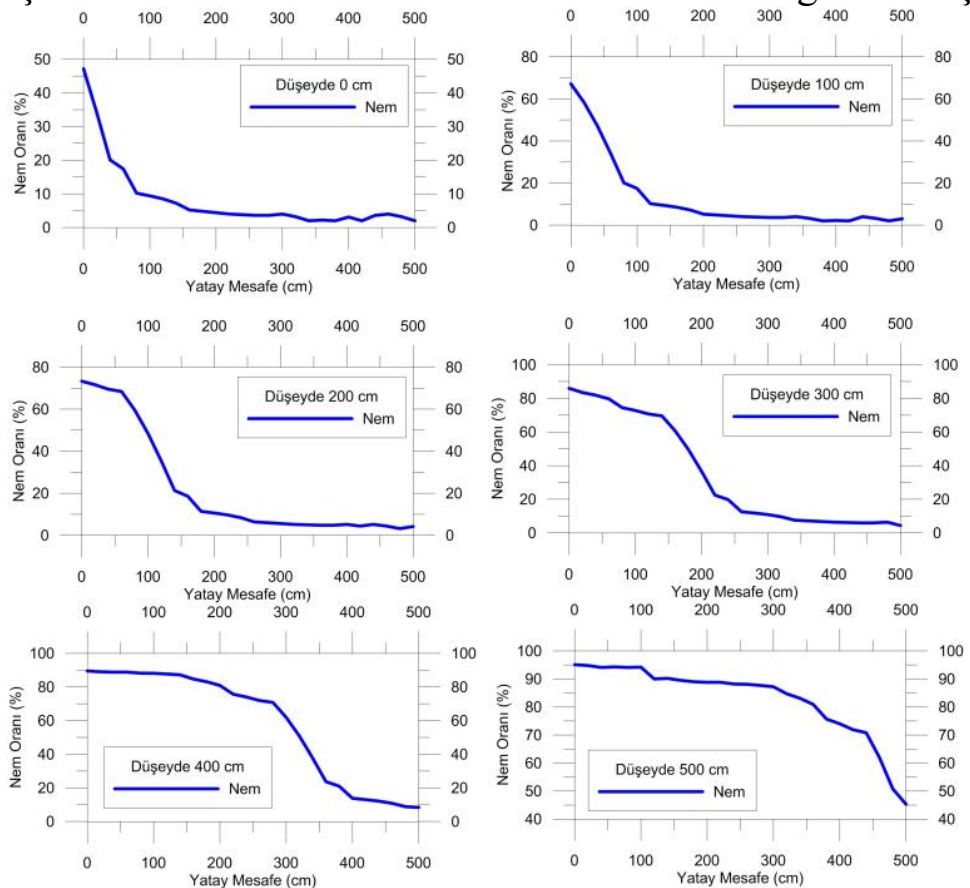

Şekil 3.7. Nem ölçümü için uygulanan profil ölçümlerinin ayrı ayrı grafik gösterimi.

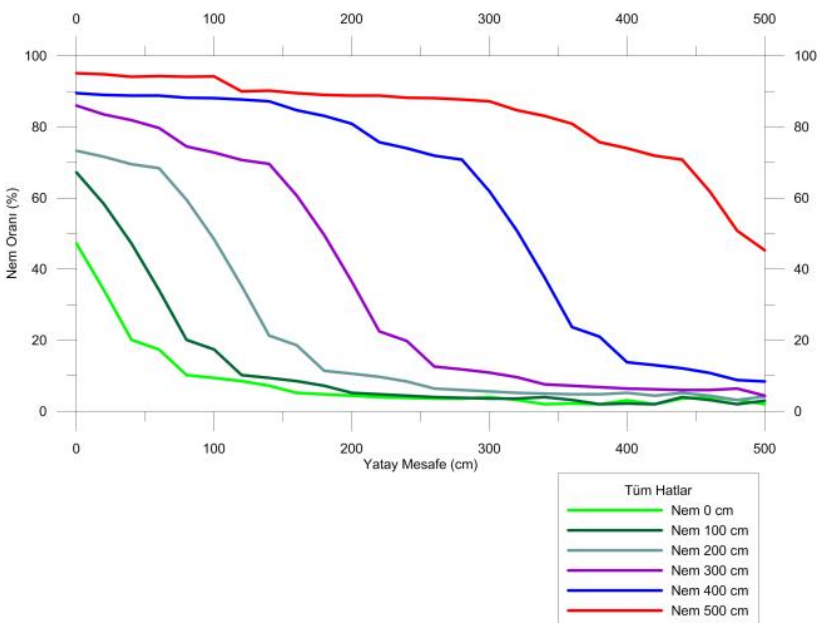

Şekil 3.8. Nem ölçümü için uygulanan profil ölçümlerinin tek grafik üzerinde gösterimi.

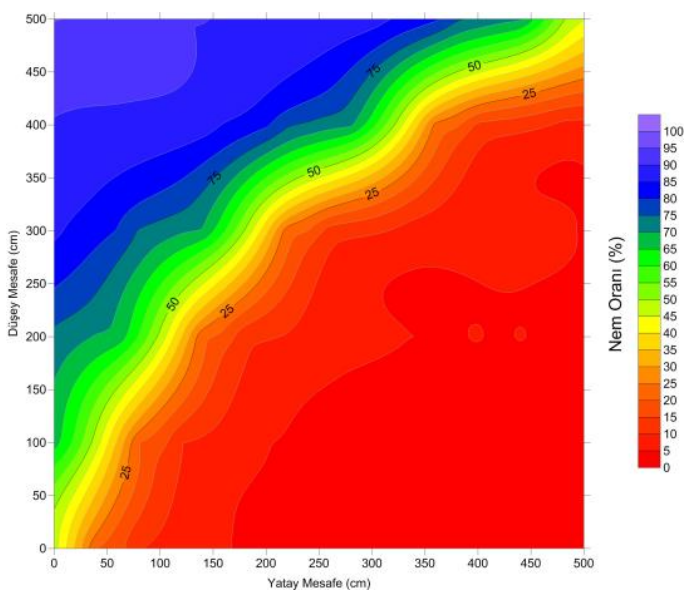

Şekil 3.9. Nem ölçümü için uygulanan profil ölçümlerinin 3 boyutlu kontür gösterimi. 
Mikrodalga nem ölçümü sonucunda elde edilen 3 boyutlu görüntüler de ölçüm yapılan duvar üzerine giydirilerek anlaşılırlığı sağlanmıştır (Şekil 3.10).

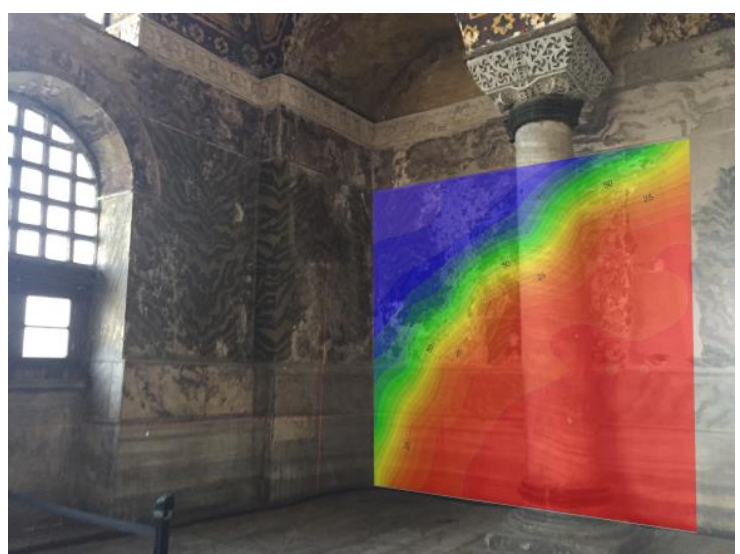

Şekil 3.10. Nem ölçümü için uygulanan profil ölçümlerinin 3 boyutlu kontür gösteriminin duvar üzerine giydirilmesi.

\section{Sonuçlar ve Tartışma}

Ayasofya Müzesinin duvarları genel olarak tuğla örgü üzeri kaplama olduğu için yıllar içerisinde aldığı 1slaklık ve nem nedeniyle bozulmalara uğramaktadır. Günümüzde de bir çok restorasyon çalışması aynı anda yürütülerek bu dünya mirasının yarınlara taşınması için çalışmalar yapılmaktadır. Bu restorasyon çalışmalarında da önemli olan problemin doğru ortaya konulmasıdır. Tarihi yapılarda duvar içi ya da zemin altını görüntülemede tahribatsız yöntemler uzun süredir tüm dünyada kullanılmaktadır. Bu yöntemlerden en yaygın ve etkili olanı yapı radarı olarak adlandırılan GPR-CX yöntemidir. Ayasofya müzesinde de bu yöntem ile çalışmalar gerçekleştirilmiş ve birçok sorunlu alan tespit edilmiştir. Bu yöntemin yanı sıra diğer tahribatsız yöntemler ile tespitlerin doğruluğunu arttırmak mümkündür. Teknolojik gelişmeler sayesinde çözünürlüğü artan termal görüntüleme ve mikrodalga nem ölçümleri tarihi eserlerin duvarlarında özellikle nem kaynaklı bozulmaların tespitinde etkili olarak kullanılmaya başlanmıştır. Bu bağlamda çalışmada tercih edilen iki yöntem Ayasofya Müzesi Galeri katında uygulanmıştır.

Elde edilen verilerin ayrı incelenmesi sonucunda önceki çalışmalarda sorunlu olduğu bilinen duvarın, yıllar içerisindeki maruz kaldığı nemden (güncel olarak da devam etmekte) hasar görmüş olabileceği ortaya konmuştur. Termal görüntüleme çalışmalarında, özellikle detay ölçümleri ile elde edilen sonuçlardaki ısıl farklılıklar duvarın içerdiği nem miktarını net olarak ortaya koymuştur (Şekil 3.6-a). Termal kamera ölçümlerinin çözünürlüğünü arttırmak için bölgesel detay ölçümlerinin yapılması ve bunların birleştirilerek haritalanmasının önemi Şekil 3.6-b'de oldukça net olarak görülmektedir. Bu doğrultuda yapılacak geniş kapsamlı ölçüm çalışmalarında termal görüntülemenin mümkün olduğunca sık aralıklı yapılması önemlidir.

Mikrodalga nem ölçümlerinde uygulama esas olarak çizgisel hatlar ile yapılmaktadır. $\mathrm{Bu}$ çizgisel hatlar mesafe ile grafiklenerek nem oranın yüksek olduğu yerler tespit edilmektedir (Şekiller 3.7 ve 3.8). Tarihi eserlerde bölgesel nemin önemli olduğu düşünüldügünde bir birine paralel oluşturulmuş hatların 3 boyut ile gridlenerek haritalanması durumun ortaya konması açısından daha fazla önem taşımaktadır (Şekil 3.9).

Gerek termal kamera görüntülerinde elde edilen 1sıl farklılık haritası gerekse mikrodalga nem ölçerde elde edilen bağıl nem haritasında olası 1slaklık bölgeleri olarak tanımlanan anomaliler 
duvar üzerinde aynı lokasyonlarda gözlemlenmiştir (Şekil 3.5 ve 3.10). Bu sonuç her iki yönteminde güvenirliliğini ispatlamakta ve daha sonra yapılacak çalışmalarda bu yöntemlerin birlikte kullanılmasının gerektiğini ortaya koymaktadır.

Termal görüntüleme ve nem ölçümleri günümüzde 1s1 kaçağ1 tespiti, su kaçağ birçok alanda yaygın olan uygulamalarda kullanılmaktadır. Bu çalışmada hedeflenen tarihi eserlere bozucu etkilerde bulunan nem gibi önemli bir unsurun ortaya çıkartılmasında da başarılı olarak her iki yöntemde kullanılmıştır.

Geçmişin mirası olan birçok tarihi eserin gelecek nesillere de aktarılması için yapısal bozuklukların en iyi şekilde tespit edilmesi büyük önem taşımaktadır. Ülkemiz gibi deprem tehlikesini her an yaşayan bir coğrafyada bulunan tarihi eserlerin olası depremlerden en az hasarla kurtulup gelecek nesillere aktarılması için yapının tüm özellikleri maruz kaldığı etkilerle birlikte tespit edilmelidir. Gelişen teknoloji sayesinde daha ulaşılabilir olan yüksek hassasiyetli cihazların (Termal Kamera ve Mikro Dalga Nem Ölçer) kullanımı yaygınlaştıkça başarı oranı da artacaktır. Gelecek çalışmalarda başlangıç olabilecek bu araştırma bu nedenle de önem taşımaktadır. Bu çalışmada elde edilen verilerin sonuçlarının en yaygın olarak kullanılan yapı radarı GPR-CX yöntemi sonuçları ile olan örtüşmesi, rahat kullanımı ve hızlı sonuç vermesi nedeniyle her iki yönteminde güvenilerek kullanılabileceğini göstermektedir.

Gerek termal görüntüleme, gerekse mikrodalga nem ölçümleri daha önceden belirlenmiş olan bölgelerde kullanıma uygun olduğu anlaşılmıştır. Bunun nedeni bu tarz yöntemlerin ikincil destek amaçlı kullanılan yöntemler olmasıdır.

\section{Teşekkür}

Bu çalışma, ÇOMÜ-BAP, FBA-2016-803 numaralı, "Eski Eserlerdeki Yapısal Tahribatların Termal Görüntüleme ve Mikrodalga Nem Ölçümleri ile Belirlenmesi: Ayasofya Müzesi Örnek Çalışması" isimli proje tarafindan desteklenmiştir.

\section{Kaynakça}

Berkmen G., 2001. Dış Cephe Yalıtım Sistemleri ve Uygulama Prensipleri, Yalıtım Kongresi ve Sergisi Bildirileri, MMO Yayını.

Bianchi F., Pisello A.L., Baldinelli G., Asdrubali F., 2014. Infrared Thermography Assessment of Thermal Bridgesin Building Envelope: Experimental Validation ina Test Room Setup. 7107-7120; doi:10.3390/su6107107.

Brodwin M., Benway J., 1980. Experimental Evaluation of a Microwave Transmission Moisture Sensor, Journal of Microwave Power 15(4): 261-265.

Chaloupka H., Ostwald O., Schiek B., 1980. Structure Independent Microwave Moisture Measurement, Journal of Microwave Power 15(4): 221-231

Cox-Smith I., 2010. Using Infrared Thermal Imaging to Audit Retrofitted Wall Insulation in Houses. BRANZ Study Report SR 232. 
Değirmenci A. İ., 2010. Türkiye'de Uygulanan Yalıtım Tekniklerinin Araştırılmasında Termal Kameranın Etkin Biçimde Kullanılması, Fen Bilimleri Enst. Yüksek Lisans Tezi.

Evangelisti L., Guattari C., Paola G., 2015. Energy Retrofit Strategies for Residential Building Envelopes: An Italian Case Study of an Early-50s Building. Sustainability 7, 10445-10460; doi:10.3390/su70810445.

Faundez-Zanuy, M., Mekyska, J., 2011. On the Focusing of Thermal Images, Pattern Recognition Letters 32, 1548-1557.

Grinzato E., 2012. IR Thermography Applied to the Cultural Heritage Conservation. 18th World Conference on Nondestructive Testing, 16-20 April 2012, Durban, South Africa.

Anonim, 2017. Termal Görüntüleyiciler (http://www.fluke.com/fluke/trtr/products/ termalgoruntuleyiciler.html)

Kosikowski M. and Suszynski Z., 2011. Processing and Recognition of the Thermal Images Using Wavelet Transforms, Microelectronics Reliability 51, 1271-1275.

Kraszewski A., 1980. Microwave aquametry - A review., Journal of Microwave Power 15(4): $261-265$

Kraszewski A.W, Trabelsi S., Nelson S.O., 1996. Moisture Content Determination in Grain by Microwave Parameters Measurement., Symposiim on Antenna Tech and Applied Electromagnetics, August 6-9, Montréal, Canada, pp.515-519.

Nelson S., Lawrence K. and Kandala C., 1992. Sensing Moisture in Peanut and Pecan Kernels by RF Impedance Measurements., Journal of Microwave Power and Electromagnetic Energy, vol.27, no.3, pp.171-174.

Nikzad S., Kari B.M., Tahmasebi F., 2011. The Application of Thermal Imaging as a Nondestructive Test in Historic Buildings. XII DBMC, Porto, Portugal.

Pleşu R., Teodoriu G., Tăranu G., 2012. Infrared Thermography Applıcations for Building Investigatıon. Buletinul Institului Politehnıc Dıı Iaşı Publicat De Universitatea Tehnică Gheorghe Asach, Din Iaşi Tomul Lv111 (Lx11), Fasc. 1, Secţia Construcţı1. Arhıtectură. 
Yalçıner ve ark. 2017

Yalçıner C.Ç., Gündoğdu E., 2017. Eski Eserlerdeki Yapısal Tahribatların Termal Görüntüleme ve Mikrodalga Nem Ölçümleri ile Belirlenmesi: Ayasofya Müzesi Örnek Çalışması. ÇOMÜ BAP FBA 2016-803, Final Raporu, 49 s.

Young M., 2014. Thermal Imaging in the Investigation of Solid Masonry Structures. The Building Conservation Directory. 